\title{
Detection of Promoter Hypermethylation of GSTP1 and CDH1 Genes and the Relationship of Histopathological Parameters of the Breast
}

\author{
Onur Eroglu1,2*, Mine Erci Baysak ${ }^{3}$, Beyhan Durak Aras ${ }^{3}$, Oguz Cilingir ${ }^{3}$, Sevilhan Artan ${ }^{3}$ \\ ${ }^{1}$ Department of Molecular Biology and Genetics, Faculty of Art and Science, Bilecik Seyh Edebali University, Bilecik, Turkey \\ ${ }^{2}$ Biotechnology Research and Application Center, Bilecik Seyh Edebali University, Bilecik, Turkey \\ ${ }^{3}$ Department of Medical Genetics, Faculty of Medicine, Osmangazi University, Eskisehir, Turkey \\ Email: *onur.eroglu@bilecik.edu.tr
}

How to cite this paper: Eroglu, O., Baysak, M.E., Aras, B.D., Cilingir, O. and Artan, S. (2018) Detection of Promoter Hypermethylation of GSTP1 and CDH1 Genes and the Relationship of Histopathological Parameters of the Breast. Advances in Breast Cancer Research, 7, 91-106.

https://doi.org/10.4236/abcr.2018.72006

Received: December 23, 2014

Accepted: March 12, 2018

Published: March 15, 2018

Copyright (C) 2018 by authors and Scientific Research Publishing Inc. This work is licensed under the Creative Commons Attribution International License (CC BY 4.0).

http://creativecommons.org/licenses/by/4.0/

\begin{abstract}
Background: Breast cancer is the most common cancer in women. Histopathology plays an important part in determining the treatment strategy for women with breast cancer. GSTP1 plays an important role in protecting cells from cytotoxic and carcinogenic agents and it is expressed in normal tissues at variable levels in different cell types. $\mathrm{CDH} 1$ plays a critical role for establishment and maintenance of polarity and differentiation of epithelium during the development period. Also, it plays an important role in signal transduction, differentiation, gene expression, cellmotility and inflammations. Methods: In this study the promoter methylation levels of GSTP1 and CDH1 gene which are associated with breast cancer were investigated by technique of Methylation Sensitive High Resolution Melting Analysis (MS-HRM). We analysed primary tumor core biopsies from 80 high-risk primary breast cancer patients (tumors $\geq 2 \mathrm{~cm}$ and/or lymphatic metastase and/or distant metastases and/or under 40 years). Also the patients' histopathologic types were associated with the methylation levels. Results: In our study the promoter hypermethylation status was observed at different rates; GSTP1 and CDH1 hypermethylation frequencies were $82 \%$ and $95 \%$ respectively. The promoter hypermethylation levels of the genes were found to be significant with lymph node positivity, ER positivity and HER2/neu negativity. Conclusion: Our study is important as being the first study that analyzes association between histopathologic type and GSTP1 and CDH1 gene promotor methylation status in Turkish population.
\end{abstract}

\section{Keywords}

Breast Cancer, Methylation, GSTP1, CDH1, Histopathological Types 


\section{Introduction}

Cancer is a process fuelled both by genetic alterations and epigenetic mechanisms. Epigenetics refer to changes in gene expression that can be mitotically inherited, but are not associated with the changes in the coding sequence of the affected genes [1]. In other words, epigenetics refer to the inheritance of information based on gene expression levels, in contrast to genetics that refer to transmission of information based on gene sequence [2].

Hypermethylation is an epigenetic change that blocks the promoter region of a gene and results in gene silencing. In breast cancer, tumor-related genes may be silenced by hypermethylation; many hypermethylated genes have been reported, and silencing of these genes plays important roles in carcinogenesis and tumor progression [3]. Identification of epigenetic changes and their correlation with other clinical factors could lead to improvements in cancer diagnosis and treatment.

Pi-class glutathione-S-transferase (GSTP1) located on chromosome 11q13 encodes a phase II metabolic enzyme that detoxifies reactive electrophilic intermediates. GSTP1 plays an important role in protecting cells from cytotoxic and carcinogenic agents and it is expressed in normal tissues at variable levels in different cell types. Altered GSTP1 activity and expression have been reported in many tumors and this is largely due to GSTP1 DNA hypermethylation at the CpG island in the promoter-5'. Glutathione S-transferase P1 (GSTP1) is a biotransformation enzyme expressedin normal breast epithelial cells which can be epigenetically inactivated in breast cancer [4].

$\mathrm{CDH} 1$ (E-cadherin) acts as a transmembrane glycoprotein that is important in epithelial cell-cell interactions, and also interacts with $\alpha$ and $\beta$ catenin together with actin in cytoskeleton [5] [6]. CDH1 plays a critical role for establishment and maintenance of polarity and differentiation of epithelium during the development period [7]. Also, it plays an important role in signal transduction, differentiation, gene expression, cellmotility and inflammations [8]. However, somatic loss of $\mathrm{CDH} 1$ expression is associated with lobular breast cancer [9]. Besides the mutational changes observed in gene expression, there are evidences for epigenetic silencing of $\mathrm{CDH} 1$ gene including promoter region methylation in CpG sites [10] [11]. Loss of CDH1 expression in cancer cells leads to a diffused growth pattern and metastasis potential in tumors; thus, $\mathrm{CDH} 1$ generally acts as a tumor suppressor gene [12].

Promoter methylation of cancer-related genes has been demonstrated to be one of the most important molecular abnormalities in cancer [13]. Aberrant DNA methylation at the cytosines of $\mathrm{CpG}$ dinucleotide-rich islands presents in the promoter region of genes; it is associated with the formation of repressive chromatin structure and leads to the silencing of gene expression. CpG island hypermethylation leads to the loss of expression of various genes involved in tumorigenesis such as tumour suppressor genes, DNA repair genes and metastasis suppressor genes. DNA methylation changes are believed to be an alternative 
pathway to cancer and therefore have the potential to be diagnostic markers that can be used in the clinical context [13]. Since DNA methylation differs in different cancer types and changes at different stages of tumour progression we have assessed whether DNA methylation profiling may be used clinically to distinguish theearly diagnosis of cancer, tumorclassification, prognosis, the regulation of treatmentprotocols, response to treatment and cancer prevention may belight onways tocontrol [14].

Thus, the objective of the present study was to evaluate 2 tumor suppressor genes ( $C D H 1, G S T P 1)$ frequently found to be methylated in breast cancers but not in normal breast tissue, when combined with the methylation-sensitive high resolution meltinganalysis methods to assess promoter methylation status, would lead to a sufficiently sensitive and specific methylation marker.

We analyzed promoter methylation in DNA from Formalin-fixed, paraffin-embedded samples collected at the time of diagnosis from 80 breast cancer cases and their normal tissue samples as controls who donated tissues from 2010 to 2011 to the Oncology Clinic in Eskişehir Osmnagazi University. Also we investigate the relation between the methylation levels and the histopathological parameters.

\section{Material and Methods}

\subsection{Sample Collection and DNA Preparation}

Formalin-fixed, paraffin-embedded samples from 80 primary breast tumors tissue samples and their normal tissue samples were collected from Eskisehir Osmangazi University, Medical Faculty, Oncology Clinic were included. Being inside eppendorf tubes; samples embedded in parafin tissue blocks as 10 sections of 10 microns thick, were taken from Eskisehir Osmangazi University of medical faculty of Pathology department. All tumor specimens have at least $70 \%$ of tumorous tissue. After deparafinization genomic DNA was extracted using MagNA Pure Compact Nucleic Acid Isolation Kit I (Roche) according to the manufacturer's instructions.

\subsection{Bisulphite Modification}

Approximately 250 - 500 nanogram of genomic DNA was bisulphite modified using the EpiTect Bisulphite kit (Qiagen) according to the manufacturer's instructions. The modified DNA was eluted three times in $50 \mu \mathrm{l}$ buffer EB. CpGenome TM Universal Methylated DNA (Chemicon/Millipore, Billerica, MA) and CpGenome Universal Unmethylated DNA were used as fully methylated and unmethylated controls, respectively. Methylation standards (under 25\%, 25\%, $50 \%, 75 \%$ and $100 \%$ ) made by diluting the fully methylated control in the unmethylated DNA were used as controls. Whole-genome amplification (WGA) was also used to make a fully unmethylated control and performed as previously described [15]. 


\subsection{Methylation-Sensitive High Resolution Melting (MS-HRM)}

Methylation analysis was performed using MS-HRM in which the approximate level of methylation and presence of heterogeneous methylation can be determined in bisulphite modified DNA [16]. Since methylated samples have more cytosines compared to unmethylated samples after bisulphite modification, the methylated samples melt later than unmethylated samples. Methylated samples with different methylation status will therefore have distinct methylated and unmethylated peaks depending on the levels of methylation. Complex melting profiles were seen in heterogeneously methylated samples as multiple heteroduplexes may be formed [17].

PCR amplification of the DNA was carried out using a Roche LightCycler 480 (Roche Applied Science, Laval, PQ, Canada) equipped with the Gene Scanning software (Version 1.5.0). MS-HRM primer details are listed in Table 1. Promoter CpG islands in the promoter were identified in each gene for designing the primers. The primers were designed according to the principles outlined previously [17]. Amplicons were generally less than 100 base pairs in size so that amplification from the majority of FFPE DNAs waspossible.

PCR was performed in a $19.5 \mu \mathrm{l}$ reaction volume and $10 \mu \mathrm{l}$ of BSC DNA templates were added to each well which contained $10 \mu$ LightCycler 480 High Resolution Melting (HRM) Master Mix (Roche), $2.5 \mu \mathrm{l} \mathrm{MgCl}_{2}$ and $3.0 \mu \mathrm{l}$ of each primer. The cycling protocol conditions included a single enzyme activation step of $10 \mathrm{~min}$ at $95^{\circ} \mathrm{C}$ followed by 50 cycles of the following steps: denaturation $95^{\circ} \mathrm{C}, 10 \mathrm{~s}$, annealing $65^{\circ} \mathrm{C}, 15 \mathrm{~s}$, and extension $72^{\circ} \mathrm{C}, 25 \mathrm{~s}$.

It is important to note that a touchdown PCR protocol as recommended by the LC480-HRM Master Mix was not adopted. Inclusion of a touchdown PCR protocol would have favoured the PCR bias towards the higher melting and thermodynamically more stable methylated DNA product.

The high resolution melting (HRM) step was performed after 50 cycles of amplification. The HRM analysis was initiated by denaturing all products at $95^{\circ} \mathrm{C}$ for $1 \mathrm{~min}$, followed by annealing at $40^{\circ} \mathrm{C}$ for $1 \mathrm{~min}$. Samples were quickly

Table 1. MS-HRM primer details (M: Methylated, U: Unmethylated, F: Forward, R: Reverse).

\begin{tabular}{c}
\hline Primers \\
\hline M-F: 5'-TTCGGG GTG TAGCGGTCGTC-3' \\
M-R: 5'-GCC CCA ATACTA AATCACGACG-3' \\
U-F: 5'-GATGTT TGG GGTGTAGTGGTT GTT-3' \\
U-R: 5'-CCA CCC CAATACTAA ATCACA ACA-3' \\
M-F: 5'-TTAGGTTAGAGG GTT ATCGCCT-3' \\
M-R: 5'-TAA CTAAAAATTCAC CTACCGAC-3' \\
U-F: 5'-TAATTTTAG GTTAGAGGGTTATTG T-3' \\
U-R: 5'-CAC AAC CAATCA ACA ACACA-3'
\end{tabular}


warmed to $65^{\circ} \mathrm{C}$ and then slowly warmed to $95^{\circ} \mathrm{C}$ at $0.1^{\circ} \mathrm{C}$ per second. Fluorescence data were collected at 25 acquisitions per second. The LC480-HRM Master $\mathrm{Mix}^{\circledast}$ employed a saturating dye (ResolLight ${ }^{\mathrm{T}}$, Roche) which facilitated the precise measurement of the melt curves of the amplicons. The Roche Gene Scanning software was employed for end product analysis. This algorithm allowed the raw melt curves to be normalized for fluorescence intensity, and a temperature shift was applied to align the normalized melt curves, which facilitated the analysis of samples with varying crossing point $(\mathrm{Cp})$ values. A difference curve was then derived from the first derivative of the melt curves. Data for the difference melt curves were exported to Excel (Office 2010; Microsoft Corp., Redmond, WA, USA) for further analysis after the graphs were plotted and inverted vertically. Both peak-height and area-under-the-curve from the normalized, temperature-shifted, difference curves were used to generate a standard curve and determine the degree of methylation of each DNA sample.

\subsection{Statistical Analysis}

Methylation levels of genes have been identified by comparing the peaks of controls and the patients' samples. Initially the patient's samples were grouped based on the prevelent prognostic factors such as age, disease stage, tumortype, lymphnode metastasis, ER, PR and HER2/neu. Then the methylation levels of these groups were compared to each other.

The v2 test and binary logistic regression were used to analyse the relationship of methylation with the clinicopathological findings. The analyses were carried out with SPSS version 17.0 (SPSS Inc., Chicago, IL). A two tailed $\mathrm{P}$-value of less than 0.05 was considered to be statistically significant for each comparison.

\section{Results}

\subsection{Patient Characteristics}

Patient characteristics included in this study are summarised in Table 2. Patients with primary breast tumors were aged between 32 and 83 (median $=58.44 \pm$ 11.09 ). Respectively $19 / 80$ cases of them (24\%) was $\leq 50$ years of age, $61 / 80$ ' $\mathrm{sin}$ $(76 \%)>50$ years of age. The selection criteria of patients are as follows. The tumors should be $2 \mathrm{~cm}$ or higher, and/or the patients have lymphatic metastase, and/or distant metastases, and/or the patients should be under 40 years old.

\subsection{Methylation Status in Primary Breast Tumor Samples}

A detail summary of the promoter hypermethylation frequencies of 2 genes in 80 primary breast tumours are shown in Table 3 and Table 4. Examples of the MS-HRM results are shown in Figures 1-8. Two genes showed detectable promoter methylation in primary breast tumours. GSTP1 and CDH1 were methylated in $82 \%$ and $95 \%$ of primary breast tumors, respectively. 
Table 2. Methylation frequecies of GSTP1.

\begin{tabular}{cc}
\hline Methylation ratio (\%) & Patient ratio (\%) \\
\hline $100 \%$ Methylated & $21 \%$ \\
$75 \%$ Methylated & $3 \%$ \\
$50 \%$ Methylated & $17 \%$ \\
$25 \%$ Methylated & $16 \%$ \\
$\downarrow 25 \%$ Methylated & $25 \%$ \\
Unmethylated & $18 \%$ \\
\hline
\end{tabular}

Table 3. Methylation frequecies of $\mathrm{CDH} 1$.

\begin{tabular}{cc}
\hline Methylation ratio (\%) & Patient ratio (\%) \\
\hline $100 \%$ Methylated & $19 \%$ \\
$75 \%$ Methylated & $40 \%$ \\
$50 \%$ Methylated & $26 \%$ \\
$25 \%$ Methylated & $10 \%$ \\
Unmethylated & $5 \%$ \\
\hline
\end{tabular}

\subsection{Correlation between DNA Methylation and Clinicopathological Parameters}

When the only methylated groups were compared, there is no correlation between the GSTP1 and CDH1 genes promoter hypermethylation and tumor stage $(\mathrm{p}>0.05)$ and age $(\mathrm{p}>0.05)$. Both CDH1 and GSTP1 genes promoter hypermethylation was found to be significant for lymph node positivity [CDH1 $=(\mathrm{p}<$ $0.05)$, GSTP1 $=(\mathrm{p}<0.001)$ ], ER positivity $(\mathrm{p}<0.05)$, and HER2/NEU negativity $(\mathrm{p}<0.05)$. The correlation details are listed in Table 5 and Table 6.

\section{Discussion}

Nowadays many studies were conducted examining several genes for epigenetic mechanisms. Methylation has been the most important field of the epigenetic changes. Most of the researchers interested in understanding the role of methylation of cancer genetics in recent years because of the methylation profiles of different genes in cancer and focused on results.

Researchers examining the changes in the genome methylation profiles have used many different techniques. With the addition of these techniques with each passing day, new methods in this research area has reached large proportions, and many clearly defined changes in gene methylation.

In recent years Methylation-sensitive high resolution melting (MS-HRM) analysis method is newly used in throughout, as well as in our country. An important feature of our study is that breast cancer cases in the methylation analysis of this method are used for the first time. 
Table 4. Associations between GSTP1 gene promoter hypermethylation and clinicopathological features of breast cancer.

\begin{tabular}{|c|c|c|c|c|}
\hline AGE & Methylated & Unmethylated & Total & $P$ value \\
\hline $\mathrm{AGE} \leq 50$ & $15(42.1)$ & 4 & 19 & \\
\hline AGE $>50$ & $51(19.7)$ & 10 & 61 & \\
\hline STAGE & & & & $\mathrm{p}>0.05$ \\
\hline STAGEII & $25(\% 38)$ & 5 & 30 & \\
\hline STAGEIII & $37(\% 56)$ & 7 & 44 & \\
\hline STAGEIV & $4(\% 6)$ & 2 & 6 & \\
\hline \multicolumn{5}{|c|}{ LYMPH NODE } \\
\hline+ & $57(86.4)$ & 11 & 68 & $\mathrm{P}<0.001$ \\
\hline- & $9(13.6)$ & 3 & 12 & \\
\hline \multicolumn{5}{|l|}{ ER } \\
\hline+ & $44(66.7)$ & 10 & 54 & $\mathrm{P}<0.05$ \\
\hline- & $22(33.3)$ & 4 & 26 & \\
\hline PR & & & & Nonevaluated \\
\hline+ & $33(\% 50)$ & 9 & 42 & \\
\hline- & $33(\% 50)$ & 5 & 38 & \\
\hline \multicolumn{5}{|l|}{ HER2/neu } \\
\hline+ & $26(39.4)$ & 4 & 30 & \\
\hline - & $40(60.6)$ & 10 & 50 & $\mathrm{P}<0.05$ \\
\hline
\end{tabular}

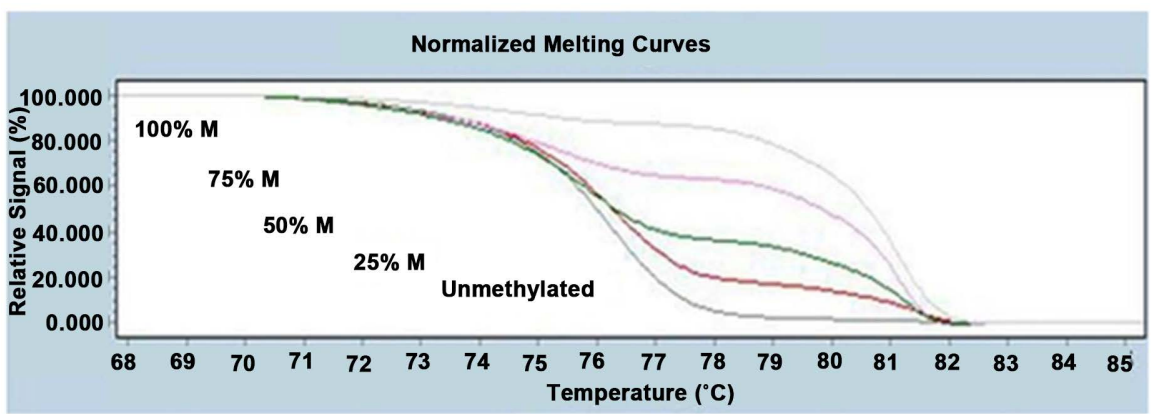

Figure 1. Melting curve shows the methylation standards (25\%, 50\%, 75\% and $100 \%)$ made by diluting the fully methylated control into the unmethylated DNA were used as controls.

A recent study examined the methylation of two genes in primary breast tumours. It is difficult to compare our results to theirs because the methodologies used are so different. Nested MSP is non-quantitative and even low amounts of background methylation will be scored whereas MS-HRM can be used for semi-quantitative estimation of methylation [17].

Breast cancer shows different clinical symptoms after being diagnosed. There are some biomarkers that are needed in order to calculate the risk of recurrence 


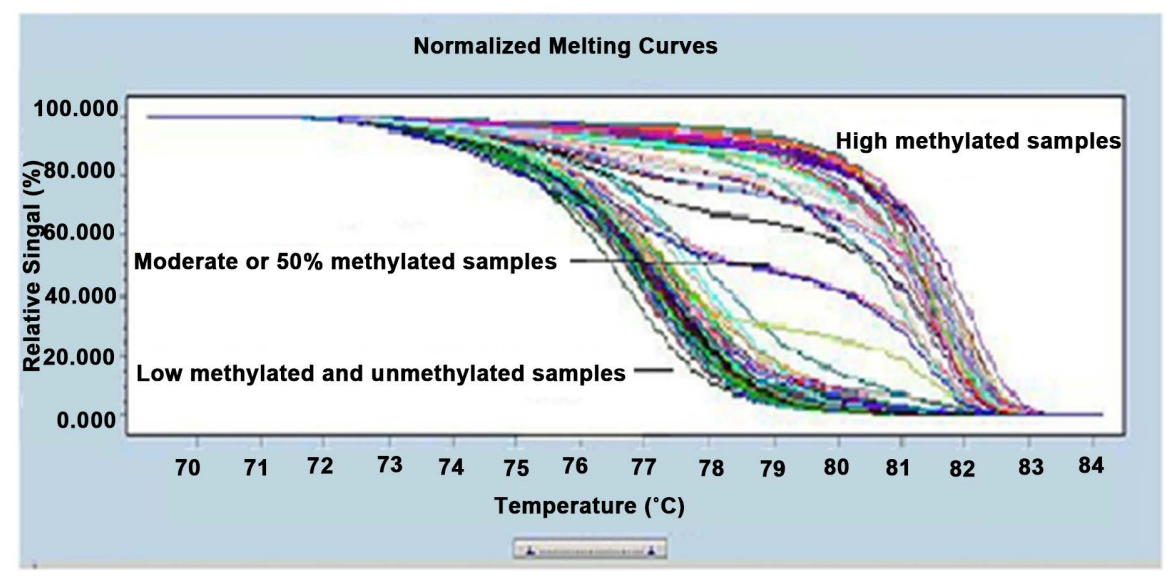

Figure 2. Melting curves of all samples.

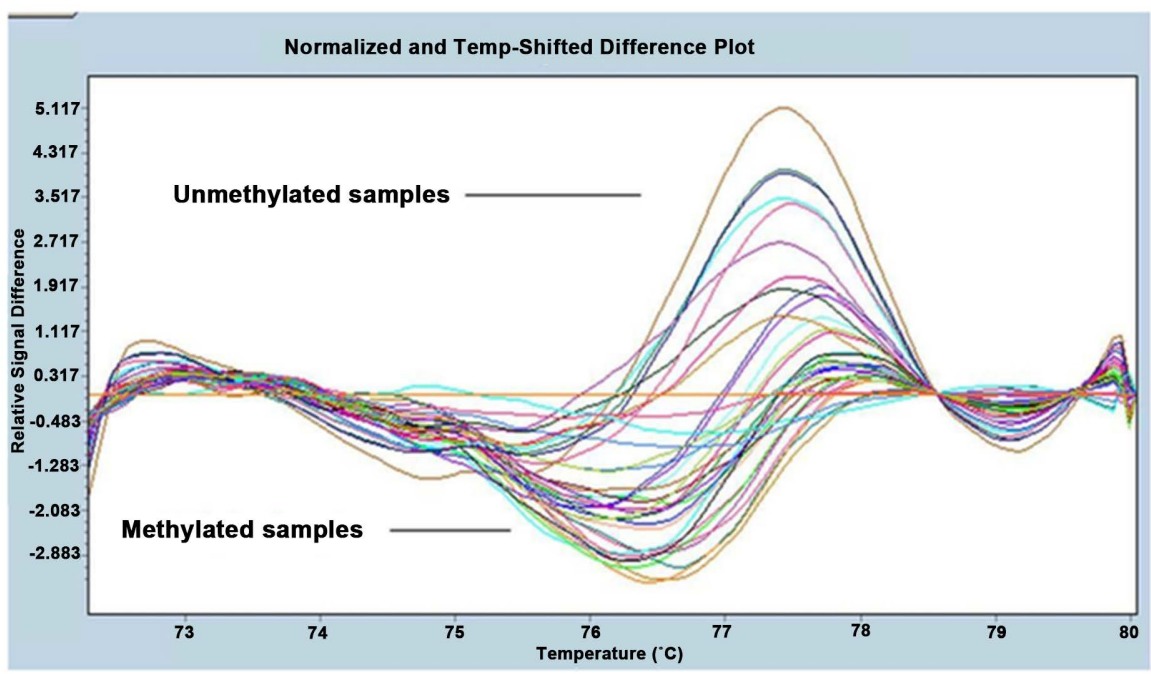

Figure 3. Melting curves of all samples of the GSTP1 gene methylated and unmethylated samples.

of the disease, identify the subgroups with poor prognosis and determine the treatment to be given. In this way, it is possible to identify groups of patients whose prognosis is very good but who can't see any advantage of systematic treatment or whose prognosis is very bad and who need to have an aggressive treatment. The standard breast cancer prognostic factors are as it follows; tumor size, lymph node involvement, histologic grad, ER and PR status. Lymph node involvement is the most powerful known prognostic factor in patients with breast cancer. The lymph node involvement has clinically been detected 50\% of breast cancer patients. Lymph node involvement is associated with tumor size but ER and PR have been found to be independent. For many years now, Steroid receptors have been used for breast cancer treatment decisions. The positivity of ER $(37 \%-80 \%)$ and PR $(45 \%-69 \%)$ rates have been reported in invasive cancers. The rate of ER-positive cells is associated with the degree of differentiation and the tumor's response to hormonal therapy. The ER-positive tumor cells ratio is associated with response of hormonal therapy and differentiation degree. 


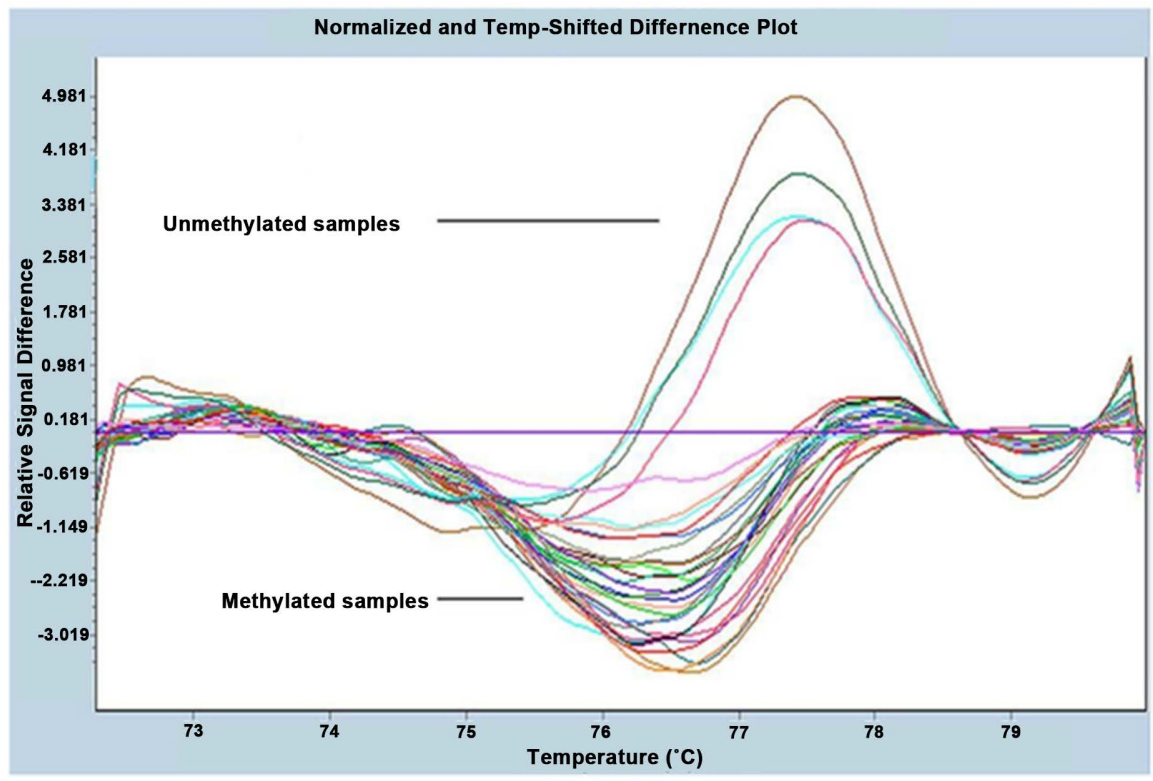

Figure 4. CDH1 gene methylated and unmethylated piks of all samples in normalized and temperature shifted difference plot by gene scanning.

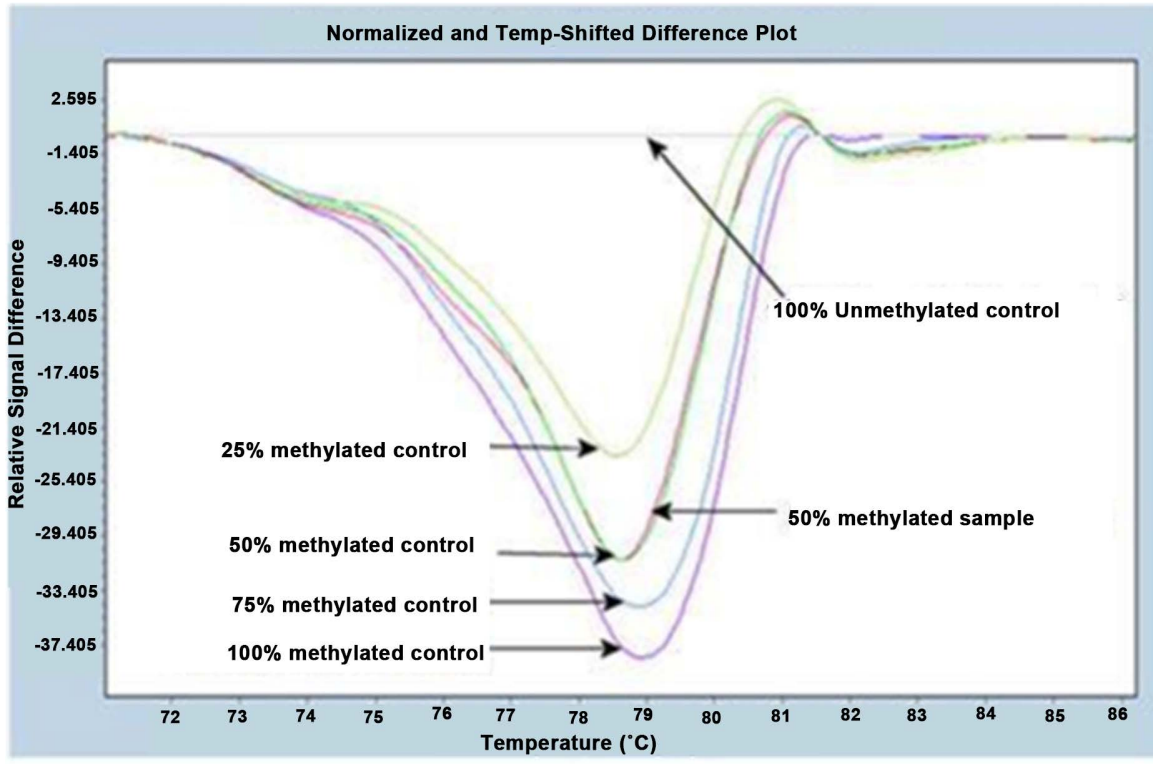

Figure 5. 50\% of methylated sample seen and the control group in normalized and temperature shifted difference plot by gene scanning.

In general, tumors have a good prognosis with high levels of ER [18]. Two high response rates to treatment of tumors are ER and PR positivity tumors. PR indicator which is likely to be a better response to endocrine treatment in case of recurrence of the disease is associated with overall survival [19] [20]. HER2/neu has also prognostic and predictive significance in breast cancer. HER2 amplification and overexpression have been reported in approximately $25 \%-30 \%$ of breast cancer patients. HER2 positivity is closely associated with the aggressive behavior of the tumor and a poor prognosis. 


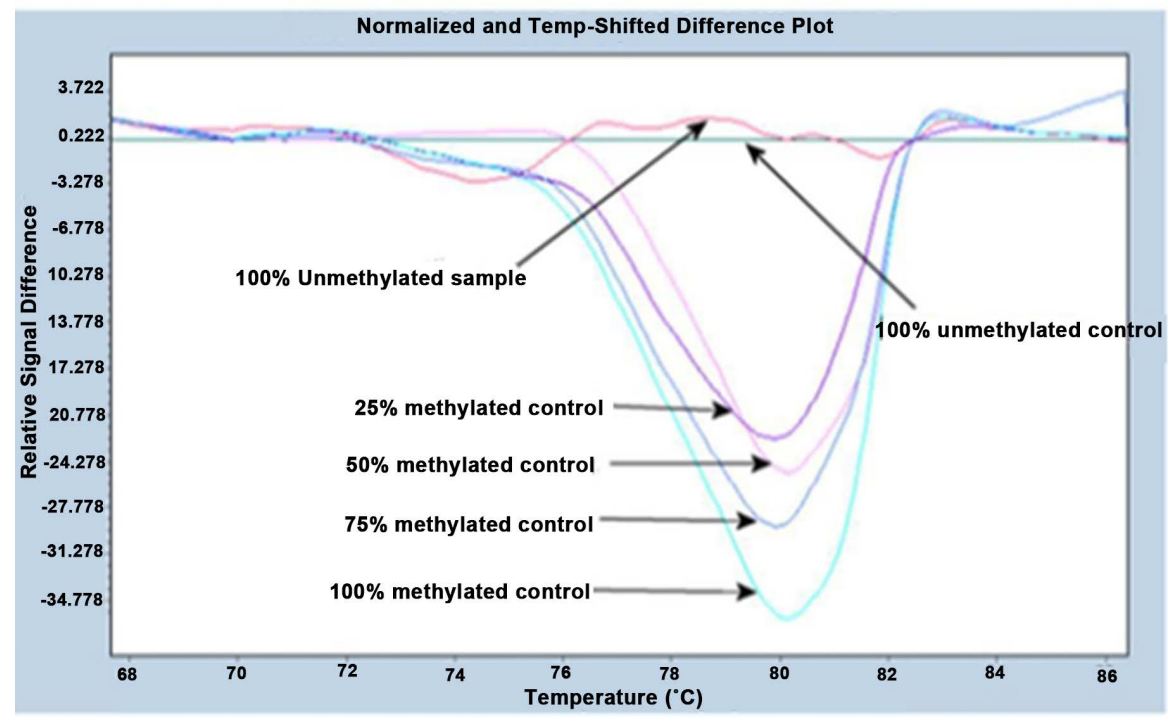

Figure $6.100 \%$ of unmethylated sample and the control group seen in normalized and temperature shifted difference plot by gene scanning.

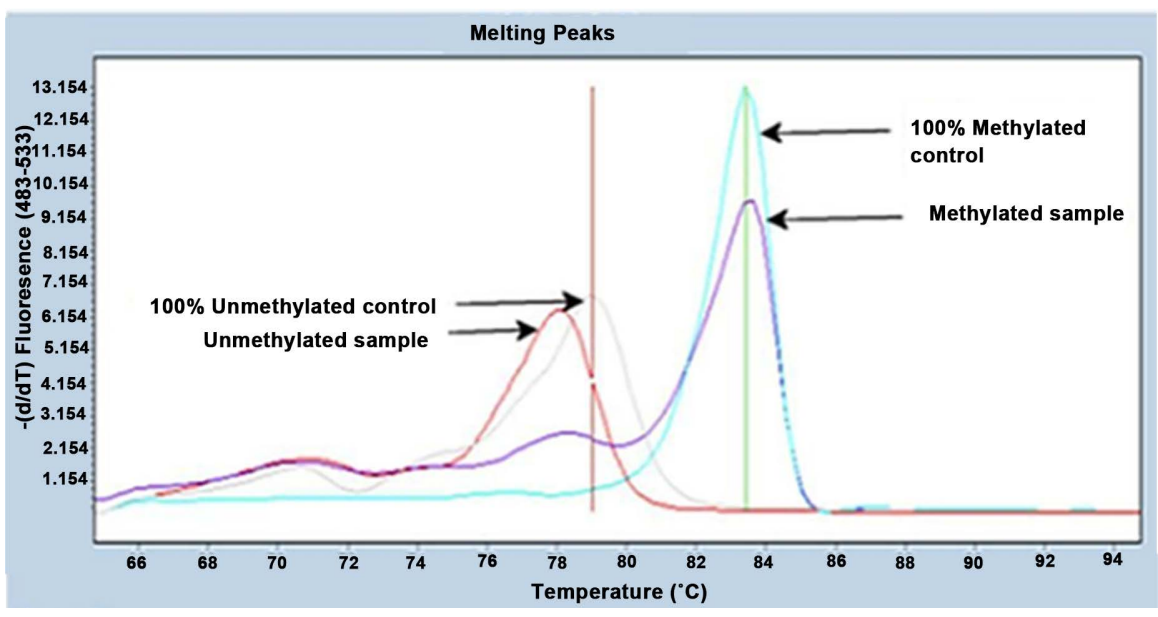

Figure 7. Melting peaks shows both unmethylated and methylated samples with controls.

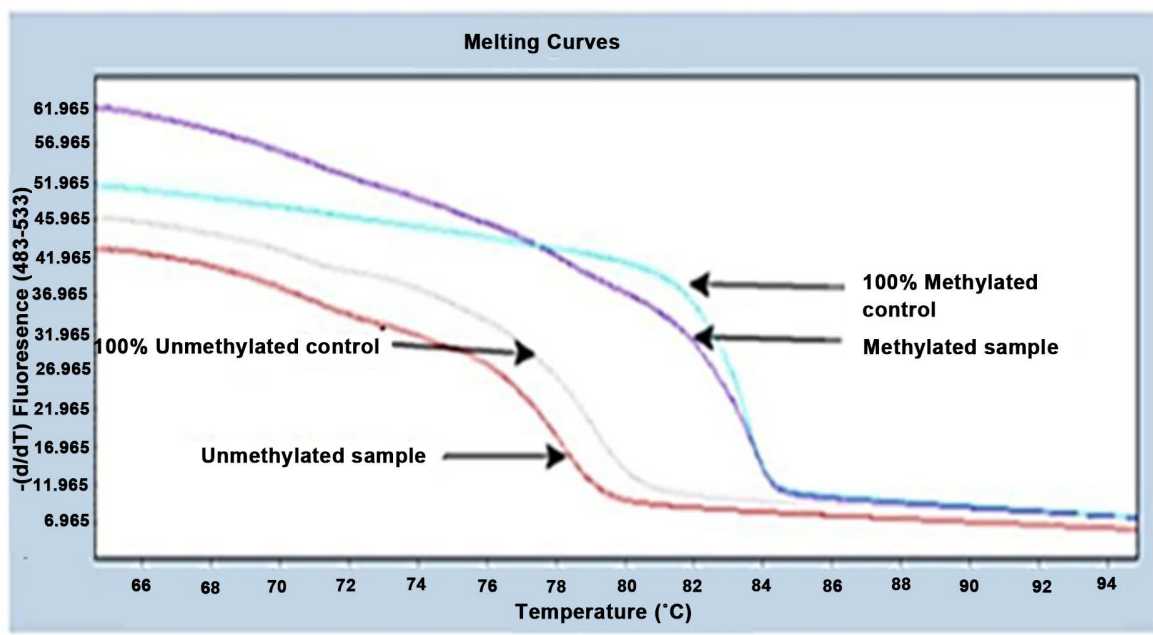

Figure 8. Melting curves of the same samples in Figure 7. 
Table 5. Associations between $\mathrm{CDH} 1$ gene promoter hypermethylation and clinicopathological features of breast cancer.

\begin{tabular}{|c|c|c|c|c|}
\hline AGE & Methylated & Unmethylated & Total & $P$ value \\
\hline $\mathrm{AGE} \leq 50$ & $17(89.5)$ & 2 & 19 & \\
\hline AGE $>50$ & $59(88.5)$ & 2 & 61 & \\
\hline STAGE & & & & $\mathrm{p}>0.05$ \\
\hline STAGEII & $28(\% 37)$ & 2 & 30 & \\
\hline STAGEIII & $42(\% 55)$ & 2 & 44 & \\
\hline STAGEIV & $6(\% 8)$ & 0 & 6 & \\
\hline \multicolumn{5}{|c|}{ LYMPH NODE } \\
\hline+ & $65(\% 85.5)$ & 3 & 68 & $\mathrm{P}<0.05$ \\
\hline- & $11(\% 14.5)$ & 1 & 12 & \\
\hline \multicolumn{5}{|l|}{ ER } \\
\hline+ & $51(\% 67.1)$ & 3 & 54 & $\mathrm{P}<0.05$ \\
\hline- & $25(\% 32.9)$ & 1 & 26 & \\
\hline PR & & & & Nonevaluated \\
\hline+ & $39(\% 51)$ & 3 & 42 & \\
\hline- & $37(\% 49)$ & 1 & 38 & \\
\hline \multicolumn{5}{|l|}{ HER2/neu } \\
\hline+ & $29(\% 38.2)$ & 1 & 30 & \\
\hline - & 47 (\%61.8) & 3 & 50 & $\mathrm{P}<0.05$ \\
\hline
\end{tabular}

According to a study, there are no correlation between histopathologic types and GSTP1 promoter hypermethylation. They found GSTP1 hypermethylation 36 out of 124 (29\%) with nested PCR method. Also they showed the methylation ratios of the patients in invazive ductal hyperplasia, in situ ductal carninomas and invazive ductal carcinomas were 4/24 (16.7\%), 18/49 (36.7\%), 14/36 (38.9\%) respectively. They showed no hypermethylation in normal breast tissues which were used for control group. The promoter hypermethylation of GSTP1 were seen in early stages of breast cancer progression. Also the frequecies of methylation increases from normal tissues to invazive ductal carcinomas [21].

In our study we found higher methylation level than as Lee et al. found [21]. We found GSTP1 hypermethylation 66 out of 80 (82\%). Our results show an increased level than comparing with the other research caused by the different technique. Nested MSP is non-quantitative and even low amounts of background methylation will not be scored whereas MS-HRM can be used for semi-quantitative estimation of methylation and it'smore sensitivity and specificity than the MSP. Also we found different rates of methylation. When we compare the histopathologic types, there is no correlation between age and tumor stage but we found GSTP1 gene promoter hypermethylation in ER(+) 44 
Table 6. Associations between gene promoter hypermethylation and clinicopathological features of breast cancer.

\begin{tabular}{|c|c|c|c|c|c|c|}
\hline \multirow{3}{*}{$\begin{array}{c}\text { Variables } \\
\text { (n) }\end{array}$} & \multirow{3}{*}{\multicolumn{2}{|c|}{$\begin{array}{c}\text { Patients } \\
(\%)\end{array}$}} & \multicolumn{2}{|c|}{ GSTP1 methylation } & \multicolumn{2}{|c|}{ CDH1 methylation } \\
\hline & & & M & $\mathrm{U}$ & M & $\mathrm{U}$ \\
\hline & & & $\mathrm{n}(\%)$ & $\mathrm{n}(\%)$ & $\mathrm{n}(\%)$ & n (\%) \\
\hline \multicolumn{3}{|c|}{ Totally: 80 patients } & $66(82)$ & $14(18)$ & $76(95)$ & $4(5)$ \\
\hline \multicolumn{7}{|c|}{ Age } \\
\hline$\leq 50$ & 19 & $(24)$ & $15(42.1)$ & 4 & $17(89.5)$ & 2 \\
\hline$>50$ & 61 & $(76)$ & $51(19.7)$ & 10 & $59(88.5)$ & 2 \\
\hline \multicolumn{7}{|c|}{ Stage } \\
\hline II & 30 & $(37.5)$ & $25(38)$ & 5 & $28(37)$ & 2 \\
\hline III & 44 & $(55)$ & $37(56)$ & 7 & $42(55)$ & 2 \\
\hline IV & 6 & $(7.5)$ & $4(6)$ & 2 & $6(8)$ & 0 \\
\hline \multicolumn{7}{|c|}{ Type of Tumor } \\
\hline IDC & 67 & $(83.75)$ & $58(86.5)$ & $9(13.5)$ & $64(95.5)$ & $3(4.5)$ \\
\hline ILC & 13 & $(16.25)$ & $8(61.5)$ & $5(38.5)$ & $12(92.3)$ & $1(7.7)$ \\
\hline \multicolumn{7}{|c|}{ Lymph Node } \\
\hline Positive & 68 & $(85)$ & $57(86.4)$ & 11 & $65(85.5)$ & 3 \\
\hline Negative & 12 & (15) & $9(13.6)$ & 3 & $11(14.5)$ & 1 \\
\hline \multicolumn{7}{|c|}{ Estrogen Receptor } \\
\hline Positive & 54 & $(67.5)$ & $44(66.7)$ & 10 & $51(67.1)$ & 3 \\
\hline Negative & 26 & $(32.5)$ & $22(33.3)$ & 4 & $25(32.9)$ & 1 \\
\hline \multicolumn{7}{|c|}{ Progesterone Receptor } \\
\hline Positive & 42 & $(52.5)$ & $33(50)$ & 9 & $39(51)$ & 3 \\
\hline Negative & 38 & $(47.5)$ & $33(50)$ & 5 & $37(49)$ & 1 \\
\hline \multicolumn{7}{|c|}{ HER2/NEU } \\
\hline Positive & 30 & $(37.5)$ & $26(39.4)$ & 4 & $29(38.2)$ & 1 \\
\hline Negative & 50 & $(62.5)$ & $40(60.6)$ & 10 & $47(61.8)$ & 3 \\
\hline
\end{tabular}

out of 66 (66.7\%) cases. Estrogen receptor (ER)-positive breast cancers are considered prognostically more favorable than ER-negative tumors.

Another study showed a correlation between 19 out of 24 (79\%) ER(+) and 13 out of $24(54 \%)$ lymph node(+) with GSTP1 promoter hypermethylation. They found GSTP1 hypermethylation 24 out of 174 (14\%) with methylation spesific PCR method. They indicated that the status of CpG islands hypermethylation of the GSTP1 gene is statistically significant prognostic factor in breast cancer [22].

In our study we found GSTP1 hypermethylation 66 out of 80 (82\%). Our results show an increased level than the other research caused bythe different technique and the tumor heterogeneity. We found ER positivity in 44 out of 66 (66.7\%) and lymph node positivity 57 out of $66(86.4 \%)$ in samples. Both results 
were similar with the Park and his colleagues.

According to Sunami et al. (2008) they analyzed 8 (RASSF1A, CCND2, GSTP1, TWIST, APC, NES1, RAR $\beta 2$ and CDH1) different genes promoter hypermethylation in 130 [(65 out of $130 \mathrm{ER}(+), 65$ out of $130 \mathrm{ER}(-)$ ] primary breast tumors by Methylation Specif PCR (MSP) [23].

For RASSF1A, CCND2, GSTP1, TWIST, and APC genes, the proportion of methylated genes was significantly higher in the ER-positive than in the ER-negative tumor group. However, no significant differences in methylation status were detected in NES1, RAR $\beta 2$, and CDH1. They were analyzed in terms of the relation between ER status and HER2/neu status. Using matched samples, no difference was found in the frequency of HER2/neu-positive tumors between the ER-negative and ER-positive groups. Then, the differences in methylation status of all eight genes were analyzed between the HER2/neu-positive and HER2/neu-negative tumor groups [23].

The proportion of methylated RASSF1A, GSTP1 and APCgenes was significantly greater in the HER2/neu-positive than in the HER2/neu-negative tumor group; no significant differences in methylation status were detected for TWIST, NES1, RAR $\beta 2$, and CCND2. Among the eight biomarkers studied, CDH1 showed predominance of methylation status in HER2/neu-negative tumors by univariate analysis [23].

Shinozaki and his colleagues (2005) analyzed 6 (RASSF1A, APC, TWIST, CDH1, GSTP1 and RAR $\beta 2$ ) genes promoter hypermethylation in 151 primary breast tumors by MSP [24]. They found CDH1 and GSTP1 promoter hypermethylation $53 \%$ and $21 \%$ respectively. When they were compared the histopathologic types (age, stage, menopausal status, tumor size, lymph node metastasis, $\mathrm{ER}, \mathrm{PR}$ ) and the promoter hypermethylation of the genes, they found the association between GSTP1 hypermethylation and lymph node metastasis; also CDH1 promoter hypermethylation and lymphovascular invasion and ER negativity were associated [24].

In our study we found CDH1 promoter hypermethylation 76 out of 80 (95\%). This is an expected result due to the fact that the CDH1 gene is an invasion gene. When we compare the histopathologic types of tumor and the methylation levels, GSTP1 promoter hypermethylation correlates with ER positivity [(51 out of $76(67.1 \%)], \mathrm{CDH} 1$ gene methylation correlates with HER2/neu negativity [(47 out of $76(61.8 \%)$ ]. This is an expected result that among large tumor size, excess number of cases with stage III and lymph node metastasis related with the HER2/neu negativity and CDH1 promoter hypermethylation.

\section{Conclusions}

Epigenetic mutation changes gene expression without any difference in DNA sequence and is effective as genetic change is in cancer formation. Promotor region hypermethylation causes gene silencing and especially important significant in neutralization of the tumour supressor genes. Determining the epigenetic changes observed in cancer cells and increasing data related to the issue is grad- 
ually becoming important in terms of prevention of cancer, determination of prognosis and development of therapeutic approaches. This situation highlights the importance of methylation as a tumor marker.

Examining the methylation profiles of $\mathrm{CpG}$ islands in cancer studies in this direction, with data provided from the early diagnosis of cancer, tumor classification, prognosis, treatment protocols, regulation, response to treatment may lead the way for controlling and preventing the cancer. For personalized treatment the quantitive results of the methylation levels of the genes are important for the use of demethylation agent for each patient. Also the promoter hypermethylation of CDH1 and GSTP1 genes can be used as a biomarker for detection of early stages of breast cancer progression.

\section{Acknowledgements}

This work was financially supported by Eskisehir Osmangazi University Research projects (grant number: 201011037) and the study was conducted in accordance with the Declaration of Helsinki, and the protocol was approved by the Ethics Committee of Eskisehir Osmangazi University (number: 2010/173). The authors wish to thank Prof. Dr. Serap Isiksoy, Assistant Prof. Dr. Evrim Ciftci and the staff for prepairing formalin-fixed parrafin embeded tissues at Eskisehir Osmangazi University medical faculty of pathology department.

\section{Author Contributions}

O.E. identified cases; prepared samples; performed methylation assays; interpreted data and analyzed data; and wrote the manuscript. M.E.B. prepared samples; deparafinization and isolation of the samples; performed methylation assays; interpreted and analyzed data. B.D.A. identified cases; interpreted and analyzed data; wrote and edited the manuscript. O.C. optimazed and performed methylation assays; conceptualized project; provided analysis; wrote and edited the manuscript. S.A. provided project oversight and coordination and analysis; wrote and edited the manuscript. All authors read and approved the final manuscript.

\section{Conflict of Interest}

We declare that there is no conflict of interest in this work.

\section{References}

[1] Etseller, M. and Herman, J.G. (2002) Cancer as an Epigenetic Disease: DNA Methylation and Chromatin Alterations in Human Tumours. The Journal of Pathology, 196, 1-7. https://doi.org/10.1002/path.1024

[2] Esteller, M. (2005) Dormant Hypermethylated Tumor Suppressor Genes: Questions and Answers. The Journal of Pathology, 205, 172-180.

https://doi.org/10.1002/path.1707

[3] Bae, Y.K., Brown, A., Garrett, E., Bornman, D., Fackler, M.J., Sukumar, S., Herman, J.G. and Gabrielson, E. (2004) Hypermethylation in Histologically Distinct Classes 
of Breast Cancer. Clinical Cancer Research, 10, 5998-6005. https://doi.org/10.1158/1078-0432.CCR-04-0667

[4] Isabelle, M. (2010) Glutathione S-Transferase pi (GSTP1). Atlas of Genetics and Cytogenetics in Oncology and Haematology, 14, 1181-1185.

[5] Kim, E.K. and Sahin, A. (2005) E-Cadherin Expression Loss in T1 İnvasive Ductal Carcinoma of Breast as a Predictive Marker for Lymph Node Metastasis. The Korean Journal of Pathology, 39, 187-191.

[6] Lombaerts, M., Wezel, T.V., Philippo, K., Dierssen, J.W.F., Zimmerman, R.M.E., Oosting, J., Eijek, R.V., Eilers, P.H., Water, B.V.D., Cornelisse, C.J., et al. (2006) E-Cadherin Transcriptional Downregulation by Promoter Methylation But Not Mutation İs Related to Epithelial-To-Mesenchymal Transition in Breast Cancer Cell Line. British Journal of Cancer, 94, 661-671. https://doi.org/10.1038/sj.bjc.6602996

[7] Wilson, B.A.R., Kaurah, P., Suriano, G., Leach, S., Senz, J., Grehan, N., Butterfield, Y.S.N., Jeyes, J., Schinas, J., Bacani, J., et al. (2004) Germline E-Cadherin Mutations in Hereditary Diffuse Gastric Cancer: Assessment of 42 New Families and Review of Genetic Screening Criteria. Journal of Medical Genetics, 41, 508-517. https://doi.org/10.1136/jmg.2004.018275

[8] Slaus, N.P. (2003) Tumor Suppressor Gene E-Cadherin and İt's Role in Normal and Malignant Cells. Cancer Cell International, 3, 1-7.

https://doi.org/10.1186/1475-2867-3-1

[9] Goldstein, N.S., Bassi, D., Watts, J.C., Layfield, L.J., Yaziji, H. and Gown, A.M. (2001) E-Cadherin Reactivity of 95 Noninvasive Ductal and Lobular Lesions of the Breast. Implications for the İnterpretation of Problematic Lesions. American Journal of Clinical Pathology, 115, 534-542. https://doi.org/10.1309/B0DD-4M7H-GJG1-7KCW

[10] Mastracci, T.L., Tjan, S., Bane, A.L., OMalley, P.F. and Andrulis, I.L. (2005) Ecadherin Alterations in Atypical Lobular Hyperplasia and Lobular Carcinoma İnsitu of the Breast. Modern Pathology, 18, 741-751.

https://doi.org/10.1038/modpathol.3800362

[11] Tischoff, I. and Tannapfel, A. (2008) DNA Methylation in Hepatocellular Carcinoma. World Journal of Gastroenterology, 14, 1741-1748. https://doi.org/10.3748/wjg.14.1741

[12] Maruyama, R, Toyooka, S., Toyooka, O.K., Harda, K. and Virmani, A.K. (2001) Aberrant Promoter Methylation Profile of Bladder Cancer and İt's Relationship to Clinicopathological Features. Cancer Research, 61, 8659-8663.

[13] Yang, X., Yan, L. and Davidson, N.L. (2001) DNA Methylation in Breast Cancer. Endocrine Related Cancer, 8, 115-127. https://doi.org/10.1677/erc.0.0080115

[14] Colot, V. and Rossignol, J.L. (1999) Eukaryotic DNA Methylation as an Evolutionary Device. BioEssays, 21, 402-411. https://doi.org/10.1002/(SICI)1521-1878(199905)21:5<402::AID-BIES7>3.0.CO;2-B

[15] Epstein, A.H., Conolly, J.L. and Gelman, R. (1989) The Predictors of Distant Relapse Following Conservative Surgery and Radiotherapy for Early Breast Cancer Are Similar to Those Following Mastectomy. International Journal Radiation Oncology Biology Physics, 17, 755-760. https://doi.org/10.1016/0360-3016(89)90062-X

[16] Wojdacz, T.K. and Dobrovic, A. (2007) Methylation-Sensitive High Resolution Melting (MS-HRM): A New Approach for Sensitive and High-Throughput Assessment of Methylation. Nucleic Acids Research, 35, 6-41. https://doi.org/10.1093/nar/gkm013

[17] Wojdacz, T.K., Moller, T.H., Thestrup, B.B., Kristensen, L.S. and Hansen, L.L. 
(2010) Limitations and Advantages of MS-HRM and Bisulfite Sequencing for Single Locus Methylation Studies. Expert Review of Molecular Diagnostics, 10, 575-580. https://doi.org/10.1586/erm.10.46

[18] Francis, G., Beadlet, G., Thomas, S. and Mengersen, K. (2206) Evalution of Estrogen and Progesterone Receptor Status in HER-2 Positive Breast Carcinomas and Correlation with Outcome. Pathology, 38, 391-398. https://doi.org/10.1080/00313020600922488

[19] Putti, T.C., Abd El-Rehim, D.M. and Rakha, E. (2005) Etsrogen Receptor-Negative Breast Carcinomas: A Review of Morphology and Immunophenotypical Analysis. Modern Pathology, 18, 26-35. https://doi.org/10.1038/modpathol.3800255

[20] Rakha, A.E., El Sayed, E.A., Green, R.A. and Lee, H.S.A. (2007) Prognostic Markers in Triple-Negative Breast Cancers. Cancer, 1, 109 p.

[21] Lee, J.S. (2007) GSTP1 Promotor Hypermetylation Is an Early Event in Breast Carcinogenesis. Virchows Archiv, 450, 637-642. https://doi.org/10.1007/s00428-007-0421-8

[22] Park, S.Y., Kim, B.H., Kim, J.H., Cho, N.Y., Choi, M. and Yu, E.J. (2007) Methylation Profiles of CpG İsland Loci in Major Types of Human Cancers. Journal of Korean Medical Science, 22, 311-317. https://doi.org/10.3346/jkms.2007.22.2.311

[23] Sunami, E., Shinozaki, M., Sim, M.S., Nguyen, S.L., Vu, A.T., Giuliano, A.E. and Hoon, D.S.B. (2008) Estrogen Receptor and HER2/Neu Satatus Affect Epigenetic Differences of Tumor-Related Genes in Primary Breast Tumors. Breast Cancer Research, 10, R46. https://doi.org/10.1186/bcr2098

[24] Shinozaki, M., Hoon, H.S., Giuliano, A.E., Hansen, N.M., Wang, H.J., Turner, R. and Taback, B. (2005) Distinct Hypermethylation Profile of Primary Breast Cancer Is Associated with Sentinel Lymph Node Metastasis. Clinical Cancer Research, 15, 2156-2162. https://doi.org/10.1158/1078-0432.CCR-04-1810.

\section{Abbreviations}

ER: Estrogen receptor;

PR: Progesterone receptor;

M: Methylation;

UM: Unmethylation;

MS-HRM: Methylation-sensitive high resolution melting;

ER: Estrogen receptor;

PR: Progesterone receptor;

PCR: Polymerase chain reaction;

CDH1: Cadherin-1; GSTP1: Glutathione S-transferase P;

HER2/neu: Human epidermal growth factor receptor 2;

F: Forward; R: Reverse. 